\title{
A comparative study of GaSb (100) surface passivation by aqueous and nonaqueous solutions
}

\author{
Z. Y. Liu and T. F. Kuech ${ }^{\text {a) }}$ \\ Department of Chemical Engineering, University of Wisconsin-Madison, Madison, Wisconsin, 53706 \\ D. A. Saulys \\ Materials Research Science and Engineering Center, University of Wisconsin-Madison, Madison, \\ Wisconsin, 53706
}

(Received 7 April 2003; accepted 31 July 2003)

\begin{abstract}
We report a nonaqueous passivation regime consisting of $\mathrm{Na}_{2} \mathrm{~S} /$ benzene/15-crown-5/oxidant. The use of a nonpolar, aprotic organic medium required the addition of a specific chelating agent (15-crown-5) to solubilize sodium sulfide, and organic oxidizing agents (anthraquinone, benzophenone, etc.) to act as electron acceptors. The surface optical and chemical properties of $\mathrm{GaSb}$ surfaces after aqueous and nonaqueous sulfide treatments were compared. Nonaqueous passivation resulted in higher photoluminescence (PL) intensity, lower oxide content, and a less amount of elemental $\mathrm{Sb}$ than aqueous passivation. The PL intensity from passivated surfaces was correlated with the standard reduction potentials of electron acceptors. (C) 2003 American Institute of Physics. [DOI: 10.1063/1.1613994]
\end{abstract}

The surface properties of semiconductors are crucial determinants of device performance. Considerable efforts have been made to modify III-V semiconductor surfaces in order to improve electronic properties and device performance. The passivation of GaAs with aqueous solutions of sodium or ammonium sulfides has been extensively studied both theoretically and experimentally. ${ }^{1-4}$ The reactions between chalcogenides and GaAs surface species change the surface electronic structures and remove the surface states from the band gap, thus unpinning the surface Fermi level and improving electrical and optical properties.

$\mathrm{GaSb}$ is an important III-V compound semiconductor for high-speed and optoelectronic device applications, the performance of which is strongly dependent on the chemical and electronic properties of GaSb surfaces or interfaces. However, GaSb is highly chemically reactive, being easily oxidized by atmospheric oxygen with the formation of native surface oxides several nanometers thick. ${ }^{5}$ An additional consequence of surface oxidation is the formation of elemental antimony at the oxide-GaSb interface, which creates a conduction channel parallel to the interface that leads to high surface leakage current, thus limiting applications. ${ }^{6,7}$ Various surface passivation methods, including wet and dry chemical processes, ${ }^{8-11}$ have been studied in efforts to improve GaSb surface characteristics. Unfortunately, most processing techniques are still water-based and lead to the growth of surface oxides and degrade the structural quality of the surface. ${ }^{5}$ Therefore, alternative, nonaqueous, solvents capable of sulfidization are of particular interest for GaSb surface processing.

In this work, a specific benzene-based sodium sulfide passivation regime was developed to improve the passivation of $\mathrm{GaSb}$ surfaces. Chelating agents were employed to solubilize and activate sulfide anions, and organic oxidizing

\footnotetext{
a) Author to whom correspondence should be addressed; electronic mail: kuech@engr.wisc.edu
}

agents were added to the passivation solution to facilitate electron transfer. The optical and chemical characteristics, before and after chemical treatments, were studied by photoluminescence (PL) and x-ray photoemission spectroscopy (XPS). A comparison of the results of GaSb passivation in aqueous and nonaqueous sulfide solutions indicated that nonaqueous passivation generates surfaces of high quality.

Samples of single-crystal, nominally undoped $p$-type and Te-doped $n$-type GaSb (100) were studied. Both $n$ - and $p$-type $\mathrm{GaSb}$ wafers had a carrier concentration of $\sim 10^{17} \mathrm{~cm}^{-3}$. A thick native oxide layer existed on the asreceived $\mathrm{GaSb}$ substrate surfaces before any chemical treatments were carried out. ${ }^{5}$ All wafers were initially degreased by sequential immersion in boiling and then cold trichloroethylene, acetone, and methanol, and were then blown dry with nitrogen. In order to reduce surface oxides, the degreased $\mathrm{GaSb}$ wafers were immersed in concentrated $\mathrm{HCl}$ for $5 \mathrm{~min}$, and then rinsed with 2-propanol. The resulting surface was flat with a thin oxide layer remaining.

The nonaqueous passivation solution contained $\mathrm{Na}_{2} \mathrm{~S}$ in anhydrous benzene. As $\mathrm{Na}_{2} \mathrm{~S}$ is insoluble in nonpolar solvents such as benzene, stoichiometric amounts (mole ratio of $\mathrm{Na}_{2} \mathrm{~S}$ to 15-crown-5 1:2) of a cation complexing agent, 15crown-5, were added to increase solubility. This procedure increased the sulfide concentration to $2 \times 10^{-3} \mathrm{gm} / \mathrm{ml}$. Small amounts of the organic oxidizing agents naphthalene, acetophenone, benzophenone, or anthraquinone were added to the solutions. The GaSb wafers were immersed in the organic sulfide solution for $1 \mathrm{~h}$ at room temperature. Upon removal, the wafers were rinsed with methanol and then blown dry with nitrogen. Aqueous sulfidization consisted of the immersion of $\mathrm{GaSb}$ wafers in a saturated $\left(0.186 \mathrm{gm} / \mathrm{ml}^{12}\right)$ $\mathrm{Na}_{2} \mathrm{~S}$ aqueous solution for $1 \mathrm{~h}$, followed by a deionized (DI) water rinse and a nitrogen blow-dry.

The surface chemical properties were investigated by XPS utilizing $\mathrm{Al} \mathrm{K} \alpha$ radiation $(h \nu=1486.6 \mathrm{eV})$ as an excitation source. Data were obtained at a chamber pressure be- 
TABLE I. Comparison of passivation results from room-temperature PL measurements

\begin{tabular}{lcc}
\hline \hline & \multicolumn{2}{c}{ Room-temperature PL intensity } \\
\cline { 2 - 3 } Treatments & $n$-type GaSb & $p$-type GaSb \\
\hline (a) Degreased & 1 & 1 \\
(b) $\mathrm{HCl}+2$-propanol & 1.4 & 1.3 \\
(c) $\mathrm{Na}_{2} \mathrm{~S}$ /DI-water & 3.5 & 3.0 \\
\hline \hline
\end{tabular}

low $5 \times 10^{-10} \mathrm{mbar}$, and recorded with a pass energy of 15 $\mathrm{eV}$, in order to determine the surface chemical bonding states, as well as to quantify the surface composition. $n$-GaSb wafers were used in the XPS studies.

The passivation efficiency of aqueous and nonaqueous solutions was evaluated by room-temperature PL peak intensity. The results for $n$ - and $p$-type GaSb surfaces are listed in Tables I and II. All of the PL measurements are referred to degreased wafers of the appropriate carrier type. Separate PL measurements, on either $n$ - or $p$-type GaSb, were referenced to PL obtained from degreased, as-received GaSb wafers of the same carrier type, that is, $n$-GaSb was used as a reference for the passivated $n$-GaSb samples. The as-received GaSb PL increased only slightly after dipping in $\mathrm{HCl}$, and was always substantially weaker in intensity than the passivated samples. In all cases, since the PL emission arises from band-to-band recombination well away from the sample surface, the spectral shape and characteristics of the PL emission in all samples did not change with passivation treatment, justifying the use of the PL peak intensity as a metric of passivation. ${ }^{13}$ The PL results presented are averages over many measurements from separately prepared samples. Aqueous sulfidization resulted in a threefold increase in PL intensity. Nonaqueous sulfidization, on the other hand, resulted in marked enhancements in PL intensity. It is crucial to point out, however, that no increase in PL intensity was observed in the absence of added organic oxidizing agents; in addition, PL intensity correlated with the standard reduction potentials of the oxidizing agents. The PL intensity exhibited by substrates passified with solutions containing the strongest oxidizing agent, anthraquinone, was enhanced more than sixfold relative to that exhibited by the reference sample.

TABLE II. Passivation results based on nonaqueous sulfide solutions consisting of $\mathrm{Na}_{2} \mathrm{~S} / 15$-crown-5/benzene, with added oxidizing agent.

\begin{tabular}{|c|c|c|c|}
\hline Oxidizing agent & $\begin{array}{l}\text { Chemical } \\
\text { structure }\end{array}$ & $\begin{array}{l}\text { Reduction } \\
\text { potential }^{\text {a }}\end{array}$ & $\begin{array}{l}\text { PL intensity } \\
n-/ p-G a S b\end{array}$ \\
\hline (1) Naphthalene & & -2.63 & $6.2 / 4.8$ \\
\hline (2) Acetophenone & & -1.58 & $7.4 / 5.4$ \\
\hline (3) Benzophenone & & -1.23 & $7.7 / 5.9$ \\
\hline (4) Anthraquinone & & -0.65 & $8.2 / 6.3$ \\
\hline
\end{tabular}

${ }^{\text {a See Ref. } 26 .}$ leaves the surface antimony-rich (Sb-to-Ga ratio of 1.51).
${ }^{\text {aSSee Ref. } 26 .}$ Downloaded 05 Mar 2007 to 128.104.198.71. Redistribution subject to AIP license or copyright, see http://apl.aip.org/apl/copyright.jsp

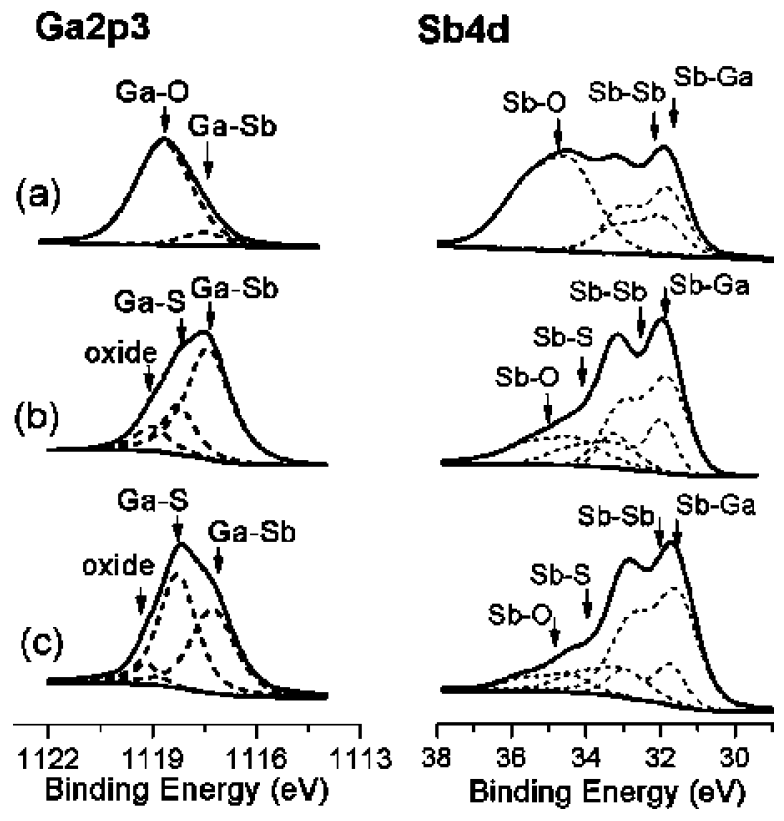

FIG. 1. Ga $2 p 3$ and $\mathrm{Sb} 4 d$ XPS spectra of $n$-GaSb after various surface treatments. (a) degreased surface (b) dipped in $\mathrm{HCl}$ for 5 min. and rinsed by 2-propanol, followed by 1-h $\mathrm{Na}_{2} \mathrm{~S}$ aqueous passivation and DI water rinse (c) dipped in $\mathrm{HCl}$ for $5 \mathrm{~min}$. and rinsed by 2-propanol, followed by 1-h $\mathrm{Na}_{2} \mathrm{~S}$ nonaqueous passivation (anthraquinone as oxidizing agent) and methanol rinse.

Surface characterization was performed by XPS analysis of $\mathrm{Ga}, \mathrm{Sb}, \mathrm{C}, \mathrm{O}, \mathrm{S}$, and $\mathrm{Cl}$ spectra recorded after each chemical treatment on $n$-GaSb. Intense oxygen signals indicated that a thick layer of oxides covered the as-received $\mathrm{GaSb}$ surface. While immersion in $\mathrm{HCl}$ reduced the amount of surface oxides, the presence of $\mathrm{Cl} 2 p$ signals indicated the generation of chloride-containing species on the GaSb surface. Figure 1 illustrates the XPS Ga2p3 and $\mathrm{Sb} 4 d$ spectra obtained after various chemical treatments, as well as the peak components to the spectra after numerical deconvolution: the $\mathrm{Ga}-\mathrm{Sb}$ bond in $\mathrm{GaSb}$ at a binding energy of $1117.4 \mathrm{eV}$ and the $\mathrm{Ga}-\mathrm{O}$ bond in $\mathrm{Ga}_{2} \mathrm{O}_{3}$ at a binding energy of $1118.8 \mathrm{eV}$. No signals due to metallic gallium were observed.

After either of the passivation treatments, all the XPS spectra exhibited similar structure with only changes in various peak intensities, as noted subsequently. The $\mathrm{Ga}_{2} \mathrm{O}_{3}$ signal was drastically reduced compared to that observed after simple immersion in $\mathrm{HCl}$ (not shown), and a peak at a higher binding energy $(1119.4 \mathrm{eV})$ became visible associated with the formation of $\mathrm{Ga}-\mathrm{OH}$ groups. ${ }^{14,15} \mathrm{We}$ attribute the component at a binding energy of $1118.2 \mathrm{eV}$ to a $\mathrm{Ga}-\mathrm{S}$ bonding state resulting from the sulfidization of the GaSb surface. The $\mathrm{Sb} 4 d$ spectra were deconvoluted into the $\mathrm{Ga}-\mathrm{Sb}$ bond in $\mathrm{GaSb}(31.7 \mathrm{eV})$, the $\mathrm{Sb}-\mathrm{O}$ bond in $\mathrm{Sb}_{2} \mathrm{O}_{3}(34.7 \mathrm{eV})$, and the $\mathrm{Sb}-\mathrm{Sb}$ bond in elemental $\mathrm{Sb}(31.9 \mathrm{eV})$, with a spin-orbit splitting of $1.25 \mathrm{eV}$ and a new peak at a binding energy of $33.2 \mathrm{eV}$ is attributed to $\mathrm{Sb}-\mathrm{S}$ species on the passivated surface.

The concentration of each component was calculated from the XPS signal area divided by the corresponding atomic sensitivity factor: 5.4 for $\mathrm{Ga} 2 p 3$ and 1.0 for $\mathrm{Sb} 4 d .{ }^{16}$ These results indicate that while the as-received GaSb surface is slightly rich in gallium, the aqueous sulfide treatment 
The nonaqueous sulfide treatments, however, yield a gallium-rich surface (Sb-to-Ga ratio of 0.56 ). The nonaqueous sulfide treatments resulted in decreased amounts of surface oxides and a larger (threefold increase) concentration of gallium sulfides on the surface than do the aqueous treatments; the concentrations of antimony sulfides are similar for the two treatments. The concentration of elemental antimony on the surface after the nonaqueous treatment $(0.06)$ is half that resulting from the aqueous treatment.

The benzene-based sulfidization of GaSb results in enhanced PL intensity, surfaces with increased sulfide coverage, and reduced oxygen and antimony content. Our choice of benzene as a solvent was motivated by the need for a solvent more inert than water. The experimental and theoretical studies ${ }^{17-19}$ have described sulfidization of III-V semiconductors as a redox process that is highly dependent on the properties (e.g., polarity) of the solvents employed.

The major drawback of inert solvents is their low solvating power. Chelation of the cation by macrocyclic polyethers ("crown ethers"), however, has been shown to solubilize inorganic salts into organic solvents. ${ }^{20}$ In our case, the magnitude of the ionic diameter of the sodium cation, $1.94 \AA{ }^{12}$ necessitated the use of 15-crown-5 (cavity diameter of 1.7 to $2.2 \AA^{20}$ ). The resulting benzene solution was sufficiently concentrated in $\mathrm{Na}_{2} \mathrm{~S}\left(2 \times 10^{-3} \mathrm{gm} / \mathrm{ml}\right)$ to effectively passivate GaSb.

Bessolov et al. have shown that sulfidization of III-V semiconductors proceeds more effectively in alcohols than in water. $^{21}$ They attribute the improvement to the lower dielectric constants of alcohols. While benzene is significantly less polar (dielectric constant ${ }^{12} \varepsilon=2.3$ ) than either water ( $\varepsilon$ $=78.5)$ or isopropanol $(\varepsilon=18.3)$, the enhanced sulfidization observed in benzene is likely due as much to the aprotic nature of the system. Anions are strongly activated by aprotic solvents, ${ }^{22}$ and the sulfide dianion, $\mathrm{S}^{2-}$, unencumbered by hydrogen bonds would be expected to be an extremely potent nucleophile with respect to the GaSb surface. This phenomenon is likely responsible for the higher concentration of surface sulfides, and reduced oxide content, after benzenebased treatments.

The sulfidization process can be described as a redox reaction: the semiconductor is oxidized, and components of the passivation solution, typically protic hydrogens, are reduced. Thus, to date, the presence of reducible protons (i.e., protic solvents) has been considered a prerequisite for an effective sulfidization solvent. ${ }^{21}$ This work demonstrates that the more general requirement is the presence of electron acceptors, which in our case are organic oxidizing agents. The presence of these electron acceptors in the passivation solution is essential, in their absence, no PL enhancements were observed. Indeed, the PL enhancements (Table II) correlate with the standard reduction potential of the additive.

The GaSb surface stoichiometry after nonaqueous treatment is antimony-poor ( $\mathrm{Sb}: \mathrm{Ga}=0.56)$, whereas aqueous treatment yields an antimony-rich surface $(\mathrm{Sb}: \mathrm{Ga}=1.51)$. Similarly, the benzene treatment leaves less elemental antimony on the surface than does the aqueous treatment. With regard to the deficit of antimony, it is intriguing to consider that the ionic diameter of $\mathrm{Sb}^{3+}\left(1.52 \AA^{23}\right)$ is significantly more compatible with the cavity diameter of 15 -crown-5 (1.7 to $\left.2.2 \AA^{20}\right)$ than is that of $\mathrm{Ga}^{3+}\left(1.24 \AA^{23}\right)$. Indeed, several complexes formed between $\mathrm{Sb}^{3+}$ species and 15-crown-5 have been isolated. ${ }^{24,25}$ Thus, the change in GaSb surface stoichiometry may result from the preferential complexation (and subsequent dissolution) of Sb cations by excess 15crown-5.

In conclusion, the sulfidization of GaSb surfaces is possible in an inert, nonpolar aprotic solvent such as benzene, provided provisions are made to solubilize sulfide salts (by the addition of crown ethers), and to facilitate electron flow into the passivation solution (by the addition of organic oxidizing agents). The degree of passivation, as measured by the PL intensity, can be modulated by the reduction potential of the added electron acceptor.

The support from Army Research Office and DARPA are gratefully acknowledged, as well as the NSF-funded UWMRSEC.

${ }^{1}$ C. J. Sandroff, R. N. Nottenburg, J. C. Bischoff, and R. Bhat, Appl. Phys. Lett. 51, 33 (1987).

${ }^{2}$ V. N. Bessolov and M. V. Lebedev, Semiconductors 32, 1141 (1998).

${ }^{3}$ C. J. Sandroff, M. S. Hedge, and C. C. Chang, J. Vac. Sci. Technol. B 7, 841 (1989).

${ }^{4}$ C. J. Spindt, D. Liu, K. Miyano, P. L. Meissner, T. T. Chiang, T. Kendelewics, I. Lindau, and W. E. Spicer, Appl. Phys. Lett. 55, 861 (1989).

${ }^{5}$ Z. Y. Liu, B. Hawkins, and T. F. Kuech, J. Vac. Sci. Technol. B 21, 71 (2003).

${ }^{6}$ G. P. Schwartz, G. J. Gualtieri, J. E. Griffiths, C. D. Thurmond, and B. Schwartz, J. Electrochem. Soc. 127, 2488 (1980).

${ }^{7}$ Z. Lu, Y. Jiang, W. I. Wang, M. C. Teich, and R. M. Osgood Jr., J. Vac. Sci. Technol. B 10, 1856 (1992).

${ }^{8}$ P. S. Dutta, K. S. R. Koteswara Rao, H. L. Bhat, and V. Kumar, J. Appl. Phys. 77, 4825 (1995).

${ }^{9}$ M. Perotin, P. Coudray, L. Gouskov, H. Luquet, C. Llinares, J. J. Bonnet, L. Soonckindt, and B. Lambert, J. Electron. Mater. 23, 7 (1994).

${ }^{10}$ J. Diaz-Reyes, E. Corona-Organiche, J. L. Herrera-Perez, and J. G. Mendoza-Alvarez, Mod. Phys. Lett. B 15, 804 (2001).

${ }^{11}$ A. Y. Polyakov, A. G. Milnes, X. L. Li, A. A. Balmashnov, and N. B. Smirkov, Solid-State Electron. 38, 1743 (1995).

${ }^{12}$ CRC Handbook of Chemistry and Physics, edited by R. C. Weast (CRC Press, Cleveland, Ohio, 1987).

${ }^{13}$ K. Mettler, Applied Phys. 12, 75 (1977).

${ }^{14}$ Z. Song, S. Shogen, M. Kawasaki, and I. Suemune, J. Vac. Sci. Technol. B 13, 77 (1995).

${ }^{15}$ C. Webb and M. Lichtensteiger, J. Vac. Sci. Technol. 21, 659 (1982).

${ }^{16}$ D. Briggs and M. P. Seah, Practical Surface Analysis, Vol. 1: Auger and $X$-ray Photoelectron Spectroscopy (Wiley, Chichester, New York, 1990).

${ }^{17}$ V. N. Bessolov, A. F. Ivankov, and M. V. Lebedev, J. Vac. Sci. Technol. B 13, 1018 (1995)

${ }^{18}$ V. N. Bessolov, E. V. Konenkova, and M. V. Lebedev, Mater. Sci. Eng., B 44, 376 (1997).

${ }^{19}$ V. N. Bessolov and M. V. Lebedev, Semiconductors 32, 1141 (1998).

${ }^{20}$ G. E. Pacey, in Lithium: Current Applications in Science, Medicine, and Technology (Wiley, New York, 1985).

${ }^{21}$ V. N. Bessolov, E. V. Konenkova, and M. V. Lebedev, J. Vac. Sci. Technol. B 14, 2761 (1996).

${ }^{22}$ J. Parker, Chem. Rev. (Washington, D.C.) 69, 1 (1969).

${ }^{23}$ U. Muller, Inorganic Structural Chemistry (Wiley, Chichester, 1993).

${ }^{24}$ R. Willey and M. Ravindran, Inorg. Chim. Acta 183, 167 (1991).

${ }^{25}$ E. Hough, D. G. Nicholson, and A. K. Vasudevan, J. Chem. Soc., Dalton Trans. 427 (1987).

${ }^{26}$ L. Meites and P. Zuman, CRC Handbook Series in Organic Electrochemistry (CRC Press, Cleveland, 1977-1987), Vol. 1. 